\title{
A PRESERVAÇÃO DO PATRIMÔNIO EM MINAS GERAIS: A "LEI RO- BIN HOOD” E OS CONSELHOS MUNICIPAIS DE PATRIMÔNIO
}

\author{
THE WAYS OF MINAS GERAIS: \\ THE HERITAGE AND THE "LAW ROBIN HOOD”
}

Luciana Christina Cruz e Souza ${ }^{1}$ e Nilson Alves de Moraes ${ }^{2}$

Recebido em: 11/11/2011

Aprovado em: 12/07/2013

\begin{abstract}
RESUMO
O trabalho aborda o processo de municipalização das responsabilidades estatais sobre a preservação do patrimônio mineiro, com foco na dinâmica estabelecida pelo Instituto Estadual do Patrimônio Histórico e Artístico de Minas Gerais (IEPHA/MG) a partir da lei estadual 12.040 de 1995 - conhecida como Lei Robin Hood. Para tanto, abarca a análise de resoluções e deliberações normativas publicadas pela agência estadual, focando-se na exigência desse Instituto sobre a instalação de conselhos municipais de patrimônio como condição para a configuração das referidas políticas municipais de preservação. O objetivo do texto é proporcionar a reflexão sobre os modelos de atuação municipal construídos pelo IEPHA/MG, considerando a capacidade do Estado (em nível estadual) em interferir nas relações entre as comunidades locais e seus bens, as quais podem influenciar leituras e interpretações sobre a região mineira a partir das patrimonializações.
\end{abstract}

Palavras-chave: patrimônio; preservação; políticas públicas

\section{Introdução: Minas Gerais, a pre- servação do patrimônio e o IEPHA}

Minas Gerais, no imaginário, nas representações e discursos sobre uma terra hospitaleira, atraente por suas riquezas culturais e ambientais, se repete, se (re)inventa em seus diferentes patrimônios. Estes, por sua vez, resultam de um trabalho de seleção e de documentação que de forma alguma é executado com neutralidade: traduz concepções, projetos, interesses e demandas dos

\begin{abstract}
The paper discusses the process of municipalization of state responsibilities on mining heritage preservation, focusing on the dynamics established by the state institute of historical and artistic heritage of Minas Gerais (IEPHA/MG) from the State Law 12.040 of 1995 - known as the Law Robin Hood. For both, the analysis covers regulatory proceedings and resolutions issued by the state agency, focusing on the requirement of the Institute on installing municipal councils equity as a condition for setting these policies municipal preservation. The purpose of the paper is to provide a reflection on the role models constructed by IEPHA/MG, considering the capacity of the State to interfere in relations between local communities and their property, which can influence readings and interpretations of the region from heritage process.
\end{abstract}

Key-words: heritage; preservation; public policy

grupos que o executam. Nesse sentido, os bens nomeados, instituídos, como patrimônio - ou seja, patrimonializados - traduzem uma percepção do mundo social e sua seleção, política, resulta de consensos negociados em arenas específicas.

Mas aqui consideramos que o Estado de Minas Gerais possui uma história de presença pública na produção e na defesa do patrimônio cultural. Nos anos 1920 foi responsável pela primeira Inspetoria Regional de Monumentos - antecipando a própria criação da Ins- 
petoria de Monumentos Nacionais em 1934 -, na década de 1970 criou o Instituto Estadual do Patrimônio Histórico e Artístico (IEPHA/MG) e elaborou a Lei 12.040 em 1995 que passou a orientar a adoção de políticas municipais específicas para o patrimônio. Essas são algumas das referências que se destacaram na história mineira pelos seus desdobramentos políticos enquanto ações de Estado voltadas à preservação do acervo cultural regional.

$\mathrm{O}$ presente texto se refere à pesquisa realizada no curso de Mestrado do Programa de Pós-Graduação em Museologia e Patrimônio nos anos de 2011 e 2012. O trabalho se refere à Lei Robin Hood, a qual estabeleceu importantes mudanças nos critérios de redistribuição de recursos tributários com foco nas ações de preservação do patrimônio, consolidando 15 anos de existência e de ampla adesão regional. $\mathrm{O}$ referido instrumento legal foi promulgado em 1995 como lei $\mathrm{n}^{\circ} 12.040$ e ficou popularmente conhecido como Lei Robin Hood em referência ao famoso herói da literatura, das baladas e canções medievais, e foi posteriormente substituído pela Lei Estadual $n^{\circ} 13.803$ no ano 2000 e pela Lei Estadual $\mathrm{n}^{\circ} 18.030$ em 2009 - mas todas elas receberam o nome de Lei Robin Hood, consagrando-se como pioneiras à prática de redistribuição do Imposto sobre Operações relativas a Circulação de Mercadorias e sobre Prestações de Serviços (ICMS) por critérios de preservação do patrimônio. Durante esse período, o Instituto Estadual do Patrimônio Histórico e Artístico de Minas Gerais (IEPHA/ MG) assumiu o papel fundamental de orientar os municípios em suas ações preservacionistas e, para tanto, elaborou modelos de atuação local através de suas resoluções e deliberações normativas.

Partindo desse quadro, o texto aborda o processo de municipalização das responsabilidades estatais sobre a preservação do patrimônio mineiro, processo esse que parece ter contribuído para a patrimonialização de inúme- ros bens culturais a nível municipal. Para tanto, o trabalho foca-se na exigência do Instituto sobre a instalação de conselhos municipais de patrimônio, considerando que os mesmos parecem assumir especial importância para a promoção da municipalização das políticas de preservação. Nessa perspectiva, a reflexão refere-se à capacidade do Estado de Minas Gerais de orientar as ações de preservação e formar/transformar as relações entre as comunidades locais e seus bens culturais, podendo influenciar leituras e interpretações sobre populações e territórios.

\section{Referencial Teórico: a Lei Robin Hood, as políticas de preservação e os conselhos municipais de patrimônio}

Ao falar sobre o patrimônio como objeto de políticas públicas, tratamos o Estado (tanto na esfera municipal, estadual e federal) como organismo, dotado de estrutura burocrática, que procura regular os movimentos da sociedade na tentativa de buscar alguma coesão, ainda que o mesmo revele antagonismos internos e produza, a partir de suas ações, conflitos externos. Atenta-se para que essa instância não seja compreendida como um compartimento separado daquilo que Jurgen Habermas (1997) chama de mundo da vida - das vivências em coletividade. Ao contrário, os sujeitos presentes na espinha dorsal do Estado se abastecem nos contextos comunicacionais da esfera pública e nas associações na esfera privada: "Isso tudo porque o sistema de ação político está embutido em contextos do mundo da vida" (HABERMAS, 1997, p. 84). Ou seja, demandas, interesses, limitações e aspirações reverberam em políticas públicas, uma vez que os agentes formuladores destas interagem socialmente nos contextos privados e públicos. Na perspectiva habermasiana, a dinamicidade das relações entre Estado e sociedade pode ser entendida pelo agir comunicativo dos sujeitos, os quais buscam a "porosidade" da esfera públi- 
ca como forma de permitir a circulação de ideias e ideologias. Agir esse que se dá na interação social, a partir da qual se tem contanto com a perspectiva do outro na construção de novas solidariedades.

Para pensar as políticas de preservação, Maria Cecília Londres Fonseca (2009) remete à ideia de "Estado em ação", introduzindo a discussão sobre a heterogeneidade, a luta de poder e o conflito de interesses que envolvem a proteção do patrimônio para se chegar a uma análise sobre a dimensão política e simbólica dos processos de seleção e institucionalização de bens culturais como patrimônios de coletividades. Para a autora, o conjunto de atividades de proteção desses bens configura-se como políticas de preservação, cuja análise demanda investigações sobre o processo de nomeação do patrimônio enquanto tal: os atores envolvidos na seleção, os objetivos que legitimam seu trabalho e o grau de envolvimento da sociedade. Para Fonseca (2009) trata-se da dimensão menos visível das políticas de preservação, mas dotada de grande importância para fins analíticos.

Mas para pensar políticas preservacionistas é preciso definir o que está sendo tratado como preservação do patrimônio. No presente trabalho optou-se por considerar a preservação como a manutenção permanente de elementos capazes de evocar a memória e a história de grupos sociais - os quais remetem a um processo de identificação e reconhecimento cultural. Esses elementos, nomeados e institucionalizados como patrimônio pelo Estado - com a participação ou não da sociedade - marcam existências no tempo: despertam sentimentos e emoções sobre o passado a partir do presente. Nessa perspectiva delineiam-se as práticas de preservação, aqui consideradas pela definição de Leila Mendes de Vasconcellos e Maria Cristina F. de Mello:

[...] a preservação é uma ação global voltada para a proteção de um bem cultural na sua totalidade, contra qualquer dano ou degradação, através de instrumentos legais. [...] A conservação, no que se refere ao patrimônio, é um termo abrangente para definir tipos de medidas destinadas a manter ou restabelecer a "saúde" física de edifícios. Existem vários graus de intervenção conservativa, o mais leve é a manutenção preventiva e o mais sofisticado é a restauração (MELLO; VASCONCELLOS, 2008, p. 62).

As autoras, ao conceituarem preservação, têm como referência a Carta de Veneza (1964) e a ideia de salvaguarda: postura que não inclui intervenções diretas, mas compreende ações políticas e instrumentos jurídicos de proteção cuja configuração revela diferentes ênfases e prioridades sociais conforme o contexto de execução.

Por esse viés, as políticas de preservação garantem - ainda que em teoria - a execução de ações de conservação e restauração que evitem as descaracterizações, o desgaste natural ou voluntário dos bens e manifestações. Entre os instrumentos legais relacionados às ações de preservação observase o tombamento e o registro, os quais evitariam ou controlariam as referidas transformações e se sustentariam por meio de documentações técnicas que justificassem e legitimassem a seleção daquilo que deveria ser preservado. Tais instrumentos revelam-se como intervenções do Estado, executadas pelo Poder Executivo em sua função atípica - a de legislar - e justificadas como de interesse público; em nível administrativo local podem ser deliberadas ou consultadas em conselhos municipais de patrimônio. Essas medidas mobilizam forças sociais na tentativa de garantir a continuidade do patrimônio no tempo, e tendem a assegurar a manutenção permanente através de ações (de conservação ou restauração) que atentam à especificidade de cada bem patrimonial, seja ele de natureza tangível ou intangível, cultural ou natural. E 
para tanto, demanda a mobilização de meios - tais como trabalhos técnicos ou mecanismos políticos - à disposição de sujeitos presentes na estrutura estatal ou terceirizados.

Interessa ressaltar que a patrimonialização de bens culturais trata-se de um processo de seleção e institucionalização de bens que são representativos de um conjunto maior de exemplares culturais. Mas a escolha desses bens é executada por agentes políticos específicos - do Estado, nas suas três esferas, da sociedade civil ou da comunidade cultural - e se revela como um trabalho de leitura, de percepção do mundo social, que ajuda a construir representações de uma região ou de uma comunidade as quais (re)formulam um ser-percebido, fazendo reconhecer uma identidade local ou regional que se considera comum, partilhada. Por essa perspectiva, o patrimônio nomeado, objeto de políticas de preservação, acaba por sustentar códigos e valores que, partilhados socialmente, influenciam interpretações sobre o mundo. Esse trabalho político e simbólico, no caso mineiro, parece ser orientado e legitimado pela agência estadual responsável por esse setor: o Instituto Estadual do Patrimônio Histórico e Artístico de Minas Gerais (IEPHA/MG). Tal Instituto foi criado pela Lei estadual $\mathrm{n}^{\mathrm{o}} 5.775$, de 30 de setembro de 1971, tendo como referência a dinâmica operacional do Serviço do Patrimônio Histórico e Artístico Nacional (SPHAN), num contexto em que as políticas de preservação do patrimônio mineiro se articulavam aos debates sobre a descentralização das responsabilidades políticas entre esferas governamentais. As discussões abarcavam as atividades preservacionistas, conferindo importância à integração das mesmas ao planejamento urbano e territorial.

Essa atribuição de importância às especificidades regionais passou a ser acompanhada por uma crescente imposição de responsabilidades à esfera municipal, concretizadas pela Constituição de 1988. A Carta Magna oficializou o dis- curso municipalista, estabelecendo que as questões de diferentes ordens pudessem ser ajustadas localmente. Ao mesmo tempo, o texto constitucional ampliou a definição de patrimônio cultural e através do seu artigo 216 atribuiu novos contornos ao seu significado. Até então, a definição conferida pela Constituinte de 1967 considerava os "[...] os documentos, as obras e os locais de valor histórico ou artístico, os monumentos e as paisagens naturais notáveis, bem como as jazidas arqueológicas" sob proteção do poder público. Atribuía-se importância aos bens associados à materialidade, fruto de ações humanas ou produtos da natureza. Em 1988, a Constituição já estendeu o conceito para os elementos intangíveis que permeiam a existência humana, considerando as manifestações e as tradições culturais representadas como bens "[...] de natureza material e imaterial, tomados individualmente ou em conjunto, portadores de referência à identidade, à ação, à memória dos diferentes grupos formadores da sociedade brasileira $[\ldots]]^{\prime 2}$.

Tal definição ampliou expressivamente o alcance das ações preservacionistas, gerando um descompasso entre as demandas e as efetivas possibilidades de atuação dos entes municipais na preservação do patrimônio local. Interessa refletir sobre o processo de descentralização das políticas preservacionistas pela perspectiva de Fernando Abrucio (2006) que atenta para a necessária articulação entre a distribuição de responsabilidades e as ações coordenadas entre os entes federativos na configuração de políticas públicas. $\mathrm{O}$ autor sustenta que o quadro instituído pela Constituição de 1988 não foi acompanhado de processos de coordenação intergovernamental, resultando numa indefinição quanto à atuação dos entes federativos.

\footnotetext{
1 Constituição de 1967, Capítulo IV, Artigo 172, Parágrafo Único. Disponível em: <http://www.planalto.gov.br/ccivil_03/Constituicao/Constituicao67.htm> Acesso em 20 de abril de 2012.

2 Constituição de 1988, Seção II, Artigo 216. Disponível em: <http:// www.planalto.gov.br/ccivil _03/Constituicao/Constituicao.htm.> Acesso em 20 de abril de 2012.
} 
[...] uma crença bem intencionada, porém ingênua, quando não perversa, instalou-se desde a Constituição de 1988: os municípios resolveriam sozinhos seus problemas de políticas públicas, bastando repassar o poder e os recursos para isso. Ora, em nossa Federação tal proposição é falsa em termos econômicos, sociais e no âmbito das instituições e da competição política local. Os governos municipais, na sua maioria, não têm renda, capital humano ou social, afora uma burocracia meritocrática, para equacionarem seus problemas coletivos e de políticas públicas sem a ajuda de um ente superior e/ou da cooperação horizontal no plano regional (ABRUCIO, 2008, p. 303-304).

A partir desse quadro, percebe-se a carência de estratégias e instrumentos voltados à capacitação de governos locais e à ação coordenada entre entes federativos. O que se observou, então, foi a insuficiência municipal para o trato de questões que exigiam algum grau de complexidade técnica e financeira para serem atendidas.

Para lidar com esse desequilíbrio, alguns estados desenvolveram, a partir da década de 1990, iniciativas legais que trouxeram novas perspectivas no campo das políticas públicas, retomando a importância da cooperação entre os entes federativos. Um dos mais conhecidos exemplos foi observado em Minas Gerais com a Lei Robin Hood que se voltava à redistribuição de recursos provenientes do $\mathrm{ICMS}^{3}$ a partir de uma série de critérios sociais. A iniciativa determinou o repasse de verbas àqueles municípios que comprovassem investimentos em educação, saúde, produção de alimentos, preservação do meio ambiente entre outros, com destaque à preservação do patrimônio cultural ${ }^{4}$.

3 Cabe destacar que o repasse do ICMS foi determinado pela Constituição de 1988 que definia em $25 \%$ a distribuição entre os municípios do valor total arrecadado, sendo $1 / 4$ desse percentual disposto conforme determinações da legislação estadual.

4 A análise do conjunto de leis que foram denominadas como Lei Robin Hood mostrou que a parcela destinada ao patrimônio cultural, em 1996 era de $0,33300 \%$ do montante destinado aos municípios. Em 1997 passou a $0,66600 \%$ e a partir de 1998 consolidou-se em $1 \%$ - percentual que se mantém nos dias de hoje.
Nesse sentido, as políticas voltadas ao patrimônio sofreram mudanças significativas: novas dinâmicas foram instituídas nos municípios mineiros como condição ao repasse de recursos provenientes do ICMS. A Lei Robin Hood pareceu evidenciar que o projeto político descentralizador não combatia as desigualdades econômicas e sociais que se desenvolviam entre os municípios e, por essa razão, adotou novos critérios de redistribuição de verbas no intuito de contemplar regiões historicamente desfavorecidas. Nesse sentido, a mediação do Estado - em sua esfera estadual - revelou-se necessária para se alcançar o que Fernando Abrucio (2006) defende como ação coordenada - no sentido de equacionar problemas coletivos e de se configurar políticas públicas. O Estado de Minas Gerais, nessa perspectiva, coordenou ações que objetivaram estimular o desenvolvimento de políticas públicas localizadas, auxiliando os municípios a minimizarem as discrepâncias entre si. A compreensão das diferenças sociais e históricas entre as localidades, e o reconhecimento de suas especificidades, foi, portanto, a válvula propulsora para o desenvolvimento de estratégias voltadas ao investimento em setores sociais.

Ainda pela perspectiva de Fernando Abrucio (2006), é possível pensar que essa cooperação realizada pelo estado mostrou-se essencial no auxílio aos municípios mais pobres, atuando com o objetivo de reduzir as desigualdades e equilibrar suas situações socioeconômicas. A Lei Robin Hood aparece, dessa forma, como indutora de políticas municipais coordenadas pelo Governo do Estado de Minas Gerais, potencializando os resultados do processo descentralizador através do incentivo financeiro à execução de ações locais.

Sobre os recursos referentes à preservação do patrimônio, coube ao IEPHA definir os critérios para a sua redistribuição. Através de pontuações, o Instituto passou a avaliar as ações adotadas pelos governos locais, possibili- 
tando repasse de verbas aos municípios que evidenciassem políticas preservacionistas. Considerando a dimensão política do processo de patrimonialização, parte-se do princípio de que as diretrizes da referida agência estadual de patrimônio traduziram, portanto, ideias, concepções e projeções de agentes políticos institucionais. Sendo assim, acabaram por interferir em realidades sociais adequando as políticas de preservação aos seus discursos. $\mathrm{O}$ que se analisa aqui são os parâmetros de atuação municipal que orientam a configuração de políticas de patrimônio através do atributo "Política Cultural Local (PCL)" definido nas Resoluções e Deliberações Normativas - que se refere às exigências do IEPHA sobre a configuração de condições e estruturas burocráticas para o repasse de recursos do ICMS. Por esse viés, a pesquisa se foca na reflexão sobre a incorporação dos conselhos municipais de patrimônio em modelos de ação adotados pelo Instituto, uma vez que as referidas instâncias se revelam como arenas projetadas para possibilitar a interação comunicativa entre o Estado e a sociedade e novos exercícios de participação política.

Para refletir sobre o tema nessa perspectiva, entendem-se os conselhos de patrimônio como espaços constituídos por diferentes sujeitos com múltiplas experiências políticas influenciadas por vivências públicas e privadas. Retomando a perspectiva de Habermas (1997) para analisar tais arenas, compreende-se que as mesmas possibilitam interações entre sujeitos sociais e políticos e são capazes de revelar as particularidades dos contextos comunicacionais de onde esses atores se originam. Trata-se de uma esfera pública onde os indivíduos poderiam discutir os interesses da sociedade em prol de decisões consensuais sobre o patrimônio.

Por esse viés, tais decisões dar-se -iam num espaço onde sujeitos com diferentes concepções de mundo, demandas e crenças - suscetíveis a constantes influências das vivências cotidianas - negociariam consensos em nome de um interesse comum. Evelina Dagnino (2002) sugere o reconhecimento dessa pluralidade como o primeiro passo para a convivência democrática nos espaços públicos, sendo um ponto de partida para o processo de busca por princípios coletivos. Em torno destes a articulação das diferenças possibilitariam a configuração do interesse comum. Para a autora, esses espaços também serviriam de canais de expressão e de reivindicação de direitos dos excluídos da cidadania, possibilitando, em casos bem sucedidos, a mobilização e o envolvimento de movimentos sociais. Nesse caso, é possível pensar que uma arena política dessa natureza possibilitaria o reconhecimento de bens culturais diversos - incluindo aqueles associados à identidade de grupos marginais - como patrimônio de uma coletividade.

\section{Método}

Para se pensar a dinâmica de seleção e nomeação do patrimônio a pesquisa focou-se no discurso elaborado e publicado nas diretrizes do IEPHA/MG para a configuração de políticas municipais de preservação. Considerando que as palavras, organizadas e estruturadas, fornecem subsídios para a compreensão de fenômenos e de conceitos compartilhados socialmente (e institucionalmente), parte-se do princípio de que as referidas normatizações configuradas pelo Instituto revelam modelos de proteção. Sendo assim, ao condicionarem as práticas municipais à contrapartida dos recursos do ICMS acabam por interferir nas decisões dos sujeitos políticos orientando a preservação ao repasse dos recursos públicos. Logo, interessa pensar as normas estabelecidas pelo Instituto na sua capacidade de definir dinâmicas de seleção e nomeação de patrimônios locais. O que se destaca aqui, portanto, é que esse exercício de escolha e de documentação de determi- 
nados bens faz ver e faz crer, confirma ou transforma, visões de mundo e de ação sobre o mundo; tratam-se de leituras, interpretações, em constante disputa (FONSECA, 2009).

Considerando que as políticas de preservação encontram-se orientadas pelo IEPHA, a pesquisa optou pela análise documental, assumindo como referência as normatizações do Instituto válidas até o ano de exercício de $2010^{5}$, sendo elas: as Resoluções 01/1996, 01/1997 e 01/2000, e as Deliberações Normativas $01 / 2002,02 / 2002$, 01/2004, 01/2005 e 01/2009, conforme quadro abaixo:

\begin{tabular}{|c|c|}
\hline Regulamentações do iepha & Ano de exercício a que se referem \\
\hline Sem regulamentação & 1996 \\
\hline Resolução 01/96 de 15 de fevereiro de 1996 & 1997 \\
\hline Resolução 01/97 de 18 de fevereiro de 1997 & $1998,1999,2000$ e 2001 \\
\hline Resolução 01/2000 de 13 de maio de 2000 & 2002 \\
\hline Deliberação 01/2002 de 11 de janeiro de 2002 & 2003 \\
\hline Deliberação 02/2002 de 27 de agosto de 2002 & 2004 e 2005 \\
\hline Deliberação 01/2004 de 30 de junho de 2004 & $2007,2008,2009$ e 2010 \\
\hline Deliberação 01/2005 de 17 de outubro de 2005 & \\
\hline
\end{tabular}

Quadro 1 - Resoluções

Fonte: dados da pesquisa

Nessas fontes foi consultado o atributo "Política Cultural Local" que se refere a um conjunto específico de critérios que avaliam a existência de uma política municipal de preservação. A pesquisa se concentrou nas exigências do IEPHA sobre a configuração de estruturas burocráticas. Por esse viés, a análise se focou na reflexão sobre a incorporação dos Conselhos Municipais de Patrimônio em modelos de ação adotados pelo IEPHA, uma vez que as referidas instâncias se revelam como arenas projetadas para possibilitar a interação comunicativa entre sujeitos políticos e novos exercícios de participação política.

Também foram analisados os relatórios publicados pelo IEPHA entre 1995 e 2010, sendo eles: "Relatório de Atividades 1995-1998", "Relatório de Gestão 1999-2002", "Relatório de Atividades 2003-2006" e "Relatório 2007-2010". Para tanto, a escolha pela abordagem de pesquisas do IBGE justifica-se pela tentativa de estabelecer referências para a reflexão sobre as políticas de preservação executas em Minas Gerais. Nessa perspectiva foi utilizado Suplemento de Cultura da Pesquisa de Informações Básicas Municipais (MU-
NIC-2006), trabalho esse realizado pelo IBGE em parceria com o Ministério da Cultura para apontamentos específicos no setor cultural, incluindo a área de patrimônio no Brasil. Todas essas fontes forneceram subsídios para a abordagem das expectativas do IEPHA e os resultados registrados pelo Instituto ao longo dos anos de vigência da Lei Robin Hood. A partir dessa escolha documental observou-se a avaliação do IEPHA sobre a institucionalização do setor cultural em âmbito municipal.

Por fim, as pesquisas provenientes da Fundação João Pinheiro - entidade pertencente ao Governo do Estado de Minas Gerais que realiza apoio técnico à Secretaria de Estado de Planejamento e Gestão - foram utilizadas como referência para a coleta de informações acerca da criação e funcionamento de estruturas burocráticas municipais. Tais dados forneceram elementos para a reflexão acerca da dinâmica pensada pelo IEPHA referente ao processo de seleção e documentação dos bens patrimonializados nas instâncias municipais.

50 referido recorte temporal limita-se ao ano de 2010 uma vez que a presente pesquisa iniciou-se em 2011, impossibilitando a abrangência deste referido ano para a análise científica. 
Cabe destacar que as referências documentais utilizadas traduzem um recorte analítico que procura compreender a dinâmica instituída pelo IEPHA em sua articulação com um repertório político-ideológico compartilhado no contexto do final do século XX e início do XXI, análise essa que se dá a partir de autores da Museologia e das Ciências Sociais. Interessa ressaltar, portanto, que a partir do discurso institucional se pretende analisar a dinâmica pensada e normatizada pela agência estadual do patrimônio, a qual serviu - e ainda serve - como referência para a configuração de políticas de preservação do patrimônio em municípios mineiros. Entendese, daí, que essa normatização orienta a seleção e a nomeação de patrimônios, influenciando leituras e interpretações, constituindo representações sobre Minas Gerais.

\section{Apresentação e discussão dos resul- tados: (re)pensando o papel dos con- selhos municipais nas políticas muni- cipais de preservação do patrimônio}

Nessa perspectiva, a pesquisa compreende a preservação do patrimônio como resultado de processos políticos e simbólicos negociados a partir de dinâmicas pensadas e normatizadas pelo IEPHA. Mas "a produção do universo simbólico é, nesse caso, o objeto mesmo da ação política" (FONSECA, 2009, p.22), daí a importância de se pensar o processo de seleção do patrimônio como elemento importante na construção de representações sobre Minas Gerais. Representações essas que tentam dar conta da pluralidade cultural de um vasto território como estratégia propiciadora de um sentimento comum de pertencimento entre seus moradores, num movimento de busca do consenso político a partir da incorporação de uma diversidade de sujeitos em arenas consultivas e deliberativas.

A análise das fontes indica que no primeiro ano de exercício após a pro- mulgação da Lei Robin Hood - 1996 - o critério da agência para permitir a adesão de municípios foi a existência, nas localidades, de bens tombados em nível federal e estadual. Mas a partir dos anos de exercício de 1997 e 1998 a agência já definiu como atributo de pontuação a existência de "Planejamento e Política Municipal de Proteção do Patrimônio Cultural" através de legislação municipal de proteção do patrimônio cultural - artigos na Lei Orgânica Municipal ou instrumentos de criação do instituto do tombamento municipal - e de equipe técnica na estrutura administrativa da Prefeitura responsabilizada pela execução das políticas na área. As fontes apontam que a partir do ano de 1999 o Instituto incluiu, entre as suas exigências, a criação de conselho municipal de patrimônio cultural como parte integrante de um aparato institucional fundamental ao trato com os bens culturais. Desde então os municípios, para se credenciarem ao repasse do ICMS pelo critério do patrimônio, precisariam atestar a existência desses conselhos, lançando mão de uma série de documentos que comprovassem a execução das atividades daquelas instâncias.

Aqui se percebe que as exigências do IEPHA para a criação de conselhos municipais de patrimônio dialogaram com as tendências contextuais de ampliação da participação social na configuração de políticas públicas. Ao que tudo indica a definição sobre a instalação de conselhos municipais de patrimônio parecia ao Instituto garantir a formulação de políticas e estruturas voltadas às demandas sociais. Seguindo as orientações do IEPHA, tais arenas foram constituídas como consultivas ou deliberativas - de acordo com a legislação de sua criação e regimento interno - por segmentos da sociedade e representantes do governo municipal. Conformando uma tendência nacional identificada no setor cultural pelo IBGE (2007), essas instâncias passaram a acompanhar e avaliar programas sobre 
a área do patrimônio, além de propor, avaliar e referendar projetos. As políticas de preservação passaram, portanto, a ter o crivo desses conselhos que se formaram como instâncias políticas de negociação de decisões referentes ao patrimônio. Sendo assim, a articulação entre Estado (na esfera municipal) e a sociedade civil tornou-se necessária à legitimação das políticas de preservação em Minas Gerais: as mesmas passariam a ter o crivo da sociedade através dos seus conselheiros.

Estudo realizado por Mônica B. L. Starling (2009) através da Fundação João Pinheiro revela que esse movimento político - apesar de instituído desde a Constituição de 1988 - ganhou força em Minas Gerais a partir da promulgação da Lei Robin Hood, indicando que tais instâncias se proliferaram entre os municípios mineiros condicionando sua atuação à redistribuição do ICMS. Segundo a autora, apenas 15 localidades haviam criado conselhos de patrimônio antes da vigência da lei, sendo elas Belo Horizonte, Betim, Cataguases, Congonhas, Divinópolis, Ituiutaba, Machado, Morro do Pilar, Santa Luzia, Paracatu, Poços de Caldas, Sete Lagoas, Três Corações, Visconde do Rio Branco e Antônio Carlos (STARLING, 2009). Quando a criação dos conselhos tornou-se uma exigência para que os municípios fossem contemplados com os recursos previstos em lei, tais instâncias difundiram-se pelo Estado de Minas Gerais, conforme os dados observados nos relatórios de gestão e de

\begin{tabular}{|c|c|c|c|c|}
\cline { 2 - 5 } \multicolumn{1}{c|}{} & $\mathbf{1 9 9 8}^{6}$ & $\mathbf{2 0 0 2}$ & $\mathbf{2 0 0 6}$ & $\mathbf{2 0 1 0}$ \\
\hline $\begin{array}{c}\text { Conselhos contabilizados pelo } \\
\text { IEPHA }\end{array}$ & 164 & 350 & 617 & $740^{7}$ \\
\hline
\end{tabular}

Quadro 2-Conselhos contabilizados pelo IEPHA

Fonte: dados da pesquisa

atividades publicados nos anos de 1998, 2002, 2006 e 2010:

Interessa ressaltar, portanto, o expressivo crescimento numérico de conselhos entre os anos de 1998 e 2002, o qual aponta o reflexo da transição entre as normatizações do IEPHA - referentes à obrigatoriedade da instalação das referidas arenas. A título de comparação com as demais regiões do país, em 2006 o Suplemento de Cultura do IBGE constatou que 13,3\% dos municípios brasileiros possuíam conselhos municipais de preservação do patrimônio (IBGE, 2007). Isso significa que os números apresentados pelo IEPHA superavam a média nacional - mais de $60 \%$ de municípios mineiros tendo conselhos instituídos - e se destacavam em relação às outras regiões do país.

[...] A distribuição geográfica dos Conselhos de Preservação do Patrimônio pelo conjunto do país e de suas regiões é bastante desigual. Observando o Cartograma 12, verifi- ca-se que a concentração ocorre nas Regiões Sul e Sudeste, mais especialmente no Estado de Minas Gerais. A maior proporção destes conselhos em Minas Gerais decorre do histórico de implementação de leis de proteção ao patrimônio que também teve neste estado sua maior incidência [...] (IBGE, 2007, p.65).

Os dados fornecidos pelo IEPHA correspondem a conselhos instituídos com diferentes nomenclaturas, ainda que destinados a consultar ou deliberar sobre temas relativos ao patrimônio. Sobre suas diferentes denominações, Isabela Biondini e outros (2010) sugere que sejam um indicativo da operacio-

6 A obrigatoriedade da instalação de conselhos municipais de patrimônio - como elemento constituinte do atributo "Política Cultural Local" - foi institu pelo IEPHA en 1999. Porto, os dalos referes a 1998 reinstituita pelo IEPHA en 199. Portanto, os dados referentes a 1998 representam iniciativas que não se articulavam à determinações específicas do Instituto.

7 Número aproximado fornecido pela Diretoria de Promoção, uma vez que o relatório 2007-2010 não fornece dados sobre a quantidade conselhos registrados pelo Instituto na referida data.

8 A referência utilizada para a abordagem dos Conselhos Municipais de Patrimênio refere-se ao estudo desenvolvido por Bondini, Souza e Star-

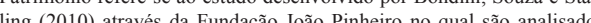
ling (2010) através da Fundação João Pinhciro no qual são analisados 385 municipios até o ano de 2005 através de atas e regimentos interno entregues ao IEPHA. 
nalização do conceito de patrimônio no âmbito político. Entre as denominações observadas no ano de $2005^{8}$, por exemplo, as pesquisadoras destacaram:

- Conselho Municipal de Patrimônio Cultural;

- Conselho Municipal de Patrimônio Histórico, Artístico e Cultural;

- Conselho Municipal de Patrimônio Cultural e Paisagístico;

- Conselho Municipal de Cultura;

- Conselho Municipal de Turismo e Patrimônio Cultural.

A partir dessas nomenclaturas acredita-se que as atividades dos conselhos estejam enquadradas na abrangência do conceito de patrimônio compartilhada entre os integrantes dessas arenas. Dessa forma, a configuração de políticas preservacionistas se articularia a concepções de patrimônio explícitas (ou implícitas) nas denominações atribuídas, seja referente à sua dimensão material ou imaterial, tangível ou intangível, cultural ou natural, ou pela perspectiva da valoração que lhe é atribuída - histórico, artístico, econômico, entre outros. O que importa destacar é que a existência dos conselhos concretiza um programa de municipalização das políticas preservacionistas que se articulava ao aparelhamento técnico local e a interlocução entre as Prefeituras e o Instituto, tendo os conselhos a função de possibilitar a participação da sociedade na configuração das políticas de preservação (IEPHA, 2002).

Sobre a composição dos conselhos, em geral destaca-se seu caráter paritário, contando com a presença de representantes de entidades religiosas, membros de associações comunitárias, profissionais liberais ou de notório saber e integrantes de associações de cunho cultural referentes às tradições populares (STARLING, 2009). Em relação às outras regiões do país, o IBGE constatou em 2006 que os conselhos municipais de patrimônio apresentavam composições que incluíam representantes de: escolas e universidades, associações com fina- lidades culturais, entidades religiosas, organizações não governamentais, associação comercial, associação de engenheiros e arquitetos, associação de moradores e fóruns regionais, Ordem dos Advogados do Brasil (OAB), entidades estudantis, conselhos regionais, Institutos Históricos e Geográficos locais, entre outros. Sua constituição, ainda de acordo com o Instituto, se daria majoritariamente por indicação do poder público, sendo em grande parte de caráter paritário (IBGE, 2007). O que se observa é que o perfil desses conselheiros parece atribuir um caráter técnico aos trabalhos executados na referida instância: os conselhos contariam com sujeitos que poderiam ser considerados "aptos" à identificação dos "valores" dos bens culturais, "detentores de conhecimentos" acadêmicos, jurídicos e políticos.

Em teoria, a composição dos conselhos municipais de patrimônio deveria contemplar diversos segmentos da sociedade e mobilizar forças para nomear patrimônios representativos da pluralidade cultural. Essa diversidade abarcada pelos conselheiros apontaria, em tese, para uma ampliação da participação da sociedade sobre as políticas de preservação, resultando em impactos mais amplos para todo o município. Nessa perspectiva, Luciana Tatagiba (2010) afirma que os princípios que assentam as formações dessas arenas é que lhes atribui uma potência democratizante: seja por sua composição plural e paritária, pela natureza pública dos acordos ou por sua competência em interferir nas ações governamentais. A autora ainda destaca que essas experiências significariam o "empoderamento" de novos atores como interlocutores válidos e a afirmação da legitimidade de novos interesses e novas demandas sociais.

Sendo assim, no plano teórico tais instâncias seriam capazes de expressar diferentes interesses e constituiriam uma arena adequada à seleção de bens culturais a serem institucionalizados como patrimônio, uma vez que traduziriam as demandas públicas - de in- 
teresse comum - pela proteção de bens de valor simbólico, capazes de evocar memórias e (re)definir identidades sociais. Através desse plano de ideias, importa pensar que as decisões ali tomadas resultam de negociações, conflitos e demandas dos grupos presentes na referida arena, os quais precisam pautarse às exigências normativas do IEPHA para atender às pontuações referentes à distribuição do ICMS.

Considerando que a configuração legal dos conselhos se dá por intervenção do Poder Executivo - responsável pela nomeação de membros efetivos e suplentes, da redação do Decreto que cria tais instâncias e dos regimentos que fundamentam suas atividades -, alguns autores defendem que essa dinâmica poderia influenciar o próprio funcionamento das arenas, pois elas se conformariam às demandas e interesses do poder público e atuariam no sentido de respaldar, de forma acrítica, as ações deste último, prejudicando o potencial democrático dos conselhos (ABRANCHES; AZEVEDO, 2004). Sobre os mecanismos de controle da atuação dos conselhos por parte do governo, Luciana Tatagiba (2010) destaca a definição da agenda, das pautas e as composições favoráveis aos interesses temáticos do governo - estas marcadas pela escolha de representantes aliados à gestão municipal vigente - como elementos que podem conformar e definir a atuação dessas arenas.

Mas Tatagiba (2010) afirma a relevância dessa instância como representação do avanço da democracia, junto com outras instituições participativas configuradas no Brasil, tais como orçamento participativo. Antônio albino Canelas Rubim (2010), por sua vez, reafirma o papel dos conselhos como mediadores entre Estado, sociedade civil e comunidade cultural, potencialmente capazes de articular interesses diferenciados na elaboração de políticas culturais. E aqui o autor chama a atenção para a possibilidade de essas arenas apresentarem uma infinidade de configurações possíveis, conformando distintas realidades.
Nesse mesmo viés, o IBGE (2007) compreende que a implementação desse modelo de participação social sobre as decisões na área de preservação do patrimônio cultural se dá em gestões democráticas, onde as políticas não se mostram concentradas no poder público. Contudo, o Instituto, na ocasião de sua pesquisa, constatou que grande parte das localidades brasileiras não apresentavam essa referida configuração política apesar de declararem a execução de ações na área patrimonial. Já naquele momento o Instituto de pesquisas destaca que Minas Gerais concentrava um número expressivo de municípios que possuíam legislação e conselho setorial - elementos que, para o IBGE, assumiam importante função na gestão democrática do patrimônio.

Sobre o papel desempenhado por esses conselhos interessa refletir a respeito das motivações que poderiam envolver a escolha dos bens a partir de uma lógica de contrapartida de recursos às ações desenvolvidas no campo do patrimônio. Nos discursos do IEPHA percebe-se, desde o princípio, que essa contrapartida financeira do ICMS revela-se como um importante estímulo para a configuração de políticas de preservação. Em seu relatório de atividades publicado em 1999, o IEPHA enaltece o aumento do número de municípios aderidos à Lei Robin Hood, destacando o repasse de recursos como elemento impulsionador do referido crescimento:

É importante registrar como é notável o efeito multiplicador, num curtíssimo espaço de tempo, de um estímulo financeiro - o incremento do ICMS - estrategicamente provocador da realização de uma potencialidade latente na maioria dos municípios. Basta comparar com os resultados, por exemplo, da exigência constitucional dos Planos Diretores que tem-se mostrado ineficaz pela falta de instrumentos concretos de estímulo e aferição de resultados (IEPHA, 1998, p. 23). 
Ao comparar a lei com outras exigências legais no âmbito das políticas públicas, o Instituto associa a ineficácia daqueles instrumentos à ausência de atrativos financeiros. Nesse sentido, os recursos do ICMS aparecem como grandes atrativos - além de condicionados - ao cumprimento dos critérios estipulados pelo IEPHA.

Nesse sentido, as fontes indicam que, para o Instituto, seria a contrapartida financeira uma das principais razões da adesão municipal à dinâmica proporcionada pela Lei Robin Hood.
Nos sucessivos relatórios de gestão e de atividades observa-se que o número de localidades inscritas no IEPHA para o repasse do ICMS aumenta expressivamente ao longo do tempo. Daí presumese que a contrapartida financeira motivou criação de conselhos por todo o Estado, os quais legitimaram sucessivos tombamentos, registros, e inventários culturais. Abaixo seguem o movimento crescente de municípios pontuados para o repasse de recursos do ICMS a partir de dados fornecidos em relatórios publicados pelo Instituto9:

\begin{tabular}{|c|c|c|c|c|c|c|c|c|c|c|c|c|c|c|c|}
\hline \multicolumn{10}{|c|}{ Número de municípios pontuados por ano de exercício } \\
\hline Ano & 1996 & 1997 & 1998 & 1999 & 2000 & 2001 & 2002 & 2003 & 2004 & 2005 & 2006 & 2007 & 2008 & 2009 & 2010 \\
\hline$N^{\circ}$ & 104 & 120 & 166 & 233 & 207 & 232 & 339 & 364 & 468 & 404 & 593 & 642 & 664 & 646 & 710 \\
\hline
\end{tabular}

Quadro 3 - Municípios pontuados por ano de exercício

Fonte: dados da pesquisa

O quadro aponta para a ampla adesão municipal ao longo de 15 anos de vigência legal, o que permite pensar sobre a proliferação de conselhos municipais de patrimônio em Minas Gerais enquanto condição do IEPHA para o desenvolvimento de políticas na área. Nessa perspectiva, é possível pensar que a expectativa do Instituto seria de que diferentes atores se fizessem presentes nessas arenas e representassem diversos interesses e demandas sociais, configurando decisões que traduziriam interesses comuns, públicos. Dessa forma, tais instâncias serviriam como ponto de partida para a articulação de princípios compartilhados referendados em projetos e leis, num movimento que Maria Cecília Londres Fonseca (2009) entende como consenso a partir da incorporação da diversidade. Para a autora, o sentido das políticas de preservação é o de recuperar a dimensão social do patrimônio que se refere a uma coletividade que não é harmônica e artificialmente representada, mas marcada por identidades múltiplas, diferenças, desigualdades e conflitos.

Mas não há como perder de vista que nos conselhos também se esta- belecem confrontos sobre monopólios de força e pela partilha de poder. Pela perspectiva de Evelina Dagnino (2002), é possível pensar que essas arenas políticas refletem a desigualdade - experimentada em sociedade - entre os grupos que ali se fazem presentes: aqueles mais organizados detêm mais recursos, competências e condições de associação e mobilização de interesses, reduzindo os atores mais pobres e marginalizados - ou até mesmo os grupos estigmatizados - ao anonimato ou, em casos extremos, ao silêncio. Estes atores ficariam sujeitos à desqualificação política por parte dos demais componentes da arena, muitas vezes por não possuírem qualificações comumente exigidas à participação nesses espaços. Qualificações essas referentes a saberes técnicos especializados - compreendidos por conhecimentos acerca do funcionamento da máquina administrativa estatal e dos aparatos legais que sustentam as políticas públicas - cuja aquisição demanda tempo e recursos financeiros, o que os grupos marginalizados, em

9 Dados disponiveis em: <http://www.iepha.mg.gov.br/servicos/icmscultural $>$ Consultado em 04 de maio de 2012. 
geral, não possuem e que se impõem, ou são impostas, como necessárias às atividades dos conselhos (DAGNINO, 2002). Aqui se percebe o que Antônio A. C. Rubim (2010) denomina como "assimetria" nas relações dos conselhos responsáveis pelo setor da cultura, destacando o nível de organização dos agentes culturais e a complexidade do campo da cultura como elementos que acabam por "escancarar" as diferenças existentes entre os atores que compõe essas referidas arenas.

Portanto, a provocação que se apresenta é a de repensar e superar dinâmicas excludentes nas quais apenas determinados atores conseguem mobilizar interesses e se organizar politicamente, fazendo predominar suas escolhas referentes ao patrimônio a ser preservado. Num processo excludente, grupos hegemônicos podem influenciar em grande medida as decisões sobre as políticas de preservação, decisões essas que vão traduzir um corpo de valores e de códigos a serem compartilhados socialmente. Nesse sentido, o patrimônio pensado e selecionado nos conselhos acaba por refletir esquemas de percepção e de pensamento que poderiam influenciar, socialmente, leituras e interpretações sobre o mundo.

Sendo assim, refletir sobre políticas de preservação exige considerar que as mesmas configuram-se a partir de escolhas elaboradas em espaços onde a pluralidade cultural se faz ou não presente, onde é ouvida ou silenciada. E é nesse locus que os consensos são negociados para responder as demandas estratégicas de seus distintos atores (ABRANCHES; AZEVEDO, 2004); demandas essas que se voltam à contrapartida de recursos do ICMS. Portanto, a seleção do que é ou não patrimônio pode ser orientada por determinados grupos - com destaque para aqueles mais organizados, com mais força política - e voltada ao que Tereza Scheiner (2008) descreve como legitimação de formas de pensamento e de ação social.
Nessa perspectiva, o Estado aqui analisado em sua esfera municipal - faz uso dos instrumentos necessários para nomear (alguns) bens como patrimônio, legitimando suas ações, então, por meio da experiência dos conselhos municipais e da consultoria de técnicos especializados. Dominique Poulot (2009, p. 13) atribui ao mundo contemporâneo ocidental dinâmicas de preservação do patrimônio em que este "[...] depende da reflexão erudita e de uma vontade política, ambos os aspectos sancionados pela opinião pública; essa dupla relação é que lhe serve de suporte para uma representação da civilização [...]". Esse exercício de escolha de determinados bens faz ver e faz crer, confirma ou transforma, visões de mundo e de ação sobre o mundo; tratam-se de leituras, interpretações, em constante disputa (FONSECA, 2009).

O tema possibilita a reflexão sobre os limites da democracia pela perspectiva do patrimônio, suscitando a problematização sobre "[...] quem tem capacidade ou possibilidade de definir e orientar ações e garantir sua continuidade ou mudança, capacidade de pautar e se fazer permanente e como o faz [...]" (MORAES, 2009, p. 03), apontando para a atuação da comunidade cultural, da sociedade civil e do Estado - aqui analisado na esfera municipal - os quais selecionam e institucionalizam o que "merece" ser preservado. Observa-se o desafio contemporâneo de dar voz à pluralidade de grupos em arenas políticas que refletem as desigualdades experimentadas no que Habermas (1997) chama "mundo da vida". Seria, portanto, nos espaços institucionalizados que se dariam os processos de comunicação entre sujeitos com realidades distintas em busca de interesses comuns, públicos. Mas o perigo que se destaca é o de se produzir a ideia de coesão social através de alguns exemplares do patrimônio, reafirmando representações isentas de diferenças: trata-se, portanto, de um movimento de neutralização das dispu- 
tas, dos conflitos. Sendo assim, as decisões configuradas nos conselhos podem incidir na construção de representações sobre Minas Gerais e suas populações, o que gera o risco de se construir uma imagem de convivência gentil da diversidade através das políticas de preservação.

\section{Considerações Finais}

Minas Gerais do imaginário, das representações, em muito se confunde, portanto, com seus patrimônios, remetendo à imagem de bens naturais e culturais que são componentes de um amplo repertório de políticas preservacionistas. Minas Gerais, e seus municípios, parecem ser a terra dos queijos, dos doces, da malha ferroviária, das montanhas e cachoeiras, das manifestações "folclóricas", da arte barroca e de tantas outras referências nomeadas como patrimônio por interesses que podem variar do simbólico ao político, do cultural ao econômico. Trata-se de imagens que resultam de um longo processo político configurado em arenas onde a sociedade (em sua diversidade) se faz ou não presente, a partir de critérios e valores de sujeitos específicos movidos por motivações determinadas. Todo esse processo encontra, por fim, respaldo nas normatizações e pontuações do IEPHA, as quais legitimam as escolhas municipais numa dinâmica em que as mesmas parecem consensuais.

Considera-se aqui a nomeação do patrimônio, oficializada pelo poder público, como parte fundamental a esse processo de configuração de políticas de preservação. Nesse sentido, é possível pensar essa referida dinâmica de seleção e nomeação como desdobramento de um trabalho de leitura, de percepção do mundo social, que se finaliza nas instâncias legitimadoras do patrimônio - como o IEPHA/MG. Mas importa destacar que nem tudo que assume importância simbólica para a comunidade é de fato patrimonializado, mas sim alguns exemplares - selecionados nas arenas consultivas ou deliberativas são tratados como referências patrimoniais. E por outro lado, nem tudo que é patrimonializado assume importância simbólica para a comunidade a que se refere. No entanto, tais seleções acabam legitimadas pelo IEPHA ao se submeterem às pontuações do Instituto através da dinâmica de contrapartida do ICMS.

Mas não há como perder de vista que essa prática, estimulada por essa dinâmica de repasses financeiros, ampliou a atuação dos municípios mineiros no campo da preservação. Minas Gerais e o IEPHA se tornaram referências nacionais nessa área e as dinâmicas preservacionistas (re)construídas a partir da promulgação da Lei Robin Hood possibilitaram a identificação e a proteção de um complexo acervo cultural, atentando o poder público - na esfera estadual - para a existência de diversificados exemplares de patrimônios locais. Nesse sentido, diferentes atores se mobilizaram nos debates e na formulação de ações voltadas à preservação do patrimônio mineiro, concentrando esforços que resultaram em complexos inventários culturais através dos quais Minas Gerais foi sucessivamente (re)interpretada.

Por esse viés, a dinâmica estabelecida entre o poder público e os conselhos municipais aponta para o desafio contemporâneo de se configurar políticas de patrimônio numa realidade multicultural em que se busca o reconhecimento (civil e jurídico) da diversidade e a garantia de manifestação da pluralidade. Espera-se que nesse campo se articulem interesses diversos para assegurar a efetiva participação de grupos subalternos e marginalizados na configuração de políticas preservacionistas. Políticas essas que devem atentar para as demandas simbólicas dos diferentes sujeitos que, em tese, se veriam representados em arenas consultivas e deliberativas. Tal quadro traduz o atual desafio de se elaborar projetos e executar políticas de preservação conciliando uma pluralidade de interesses voltados ao patrimônio. 


\section{Referências}

1. ABRANCHES, M.; AZEVEDO, S. Capacidade dos Conselhos em influenciar políticas públicas: realidade ou mito? In: Orlando Júnior (Org.). Governança Urbana e Poder Local. Rio de Janeiro: Fases, 2004.

2. ABRUCIO, F. Metrópole: território, sociedade e política - o caso da Região Metropolitana de Belo Horizonte. Belo Horizonte: Editora PUC Minas, 2008.

3. Para além da descentralização: os desafios da coordenação federativa no Brasil. In: FLEURY, S. (org). Democracia, descentralização e desenvolvimento: Brasil \& Espanha. Rio de Janeiro: Editora FGV, 2006.

4. ARIMATEIA, K. de. O ICMS cultural como estratégia de indução para a descentralização de políticas de patrimônio cultural. Cadernos da Escola do Legislativo, v. 12, p. 165-201, 2010.

5. BARACHO, M. A. P. A descentralização das ações na área do patrimônio histórico, artístico e cultural em Minas Gerais: uma agenda em aberto. Duo Informação e Cultura Textos, Belo Horizonte - Minas Gerais, v. 1, p. 1-11, 2003.

6. BELlOTTO, H. L. Da gênese à função: o documento de arquivo como prova e testemunho. In: Lídia Silva de Freitas et al. (Org.). Documento: gênese e contextos de uso. Rio de Janeiro: Editora da UFF, 2010.

7. BIONDINI, I.; SOUZA, N.; STARLING, M. A descentralização das ações na área do patrimônio cultural: o impacto da Lei Robin Hood nos municípios mineiros. XIV Seminário sobre a Economia Mineira, Diamantina. Avaliação de Políticas Públicas: Minas no Século XXI. Diamantina: UFMG, 2010.

8. BOTELHO, T. R. Patrimônio Cultural e Gestão das Cidades: uma análise da Lei ICMS Cultural de Minas Gerais. Revista Habitus, Goiânia, v.4, n.1, jan/ jun 2006, pp.471-492.

9. BOURDIEU, P. O poder simbólico. Rio de Janeiro: Bertrand Brasil, 1992.

10. BUCCI, M. P. D. Direito Administrativo e políticas públicas. São Paulo: Saraiva, 2002.

11. CALABRE, L. A cultura no âmbito federal: leis, programas e municipalização. Artigo apresentado no Seminário Cidades e Políticas Públicas. $6^{\circ}$ Fórum Sul Mineiro de Cultura. Minas Gerais, Pouso Alegre, 2011.

12. CHUVA, M. Os arquitetos da memória. Sociogênese das práticas de preservação do patrimônio cultural no Brasil (anos 1930-1940). Rio de Janeiro: UFRJ, 2009.

13. DAGNINO, E. Sociedade Civil, Espaços Públicos e a Construção Democrática no Brasil: Limites e Possibilidades. In: DAGNINO, Evelina (org.) Sociedade Civil e Espaços Públicos no Brasil. São Paulo: Paz e Terra, 2002.

14. FONSECA, M. C. L.. O Patrimônio em processo - trajetória da política federal de preservação no Brasil. Rio de Janeiro: UFRJ, 2009.

15. GONÇALVES, J. R. S. O patrimônio como categoria de pensamento. In: ABREU, Regina; CHAGAS, Mario (Org.). Memória e patrimônio: ensaios contemporâneos. Rio de Janeiro: DP\&A: Faperj: Unirio, 2003b. p. 21-29.

16. GREGORI, I. C. de. O Estatuto da Cidade: perspectivas e desafios dos novos instrumentos de reforma urbana. Disponível em: <www.nepam. unicamp.br $>$ Acesso em 10 de julho de 2012 .

17. HABERMAS, J. Consciência moral e agir comunicativo. Rio de Janeiro: Ed. Tempo Brasileiro, 1989.

18. Direito e democracia. Entre facticidade e validade. Rio de 
Janeiro: Ed. Tempo Brasileiro, 1997.

19. JODELET, D. (Org.). As representações sociais. Rio de Janeiro: EdUERJ, 2001.

20. MENDONÇA, S. R.. Estado, Violência Simbólica e Metaforização da Cidadania. Tempo. Revista do Departamento de História da UFF, RJ, v. 1, p. 94-125, 1996.

21. MONNET, J. O álibi do patrimônio: crise da cidade, gestão urbana e nostalgia do passado. In: ARANTES, Antônio Augusto (org.). Revista do Patrimônio Histórico e Artístico Nacional. Rio de Janeiro, n. 24 - Cidadania, p.220-228, 1996.

22. MORAES, N. A. de. Políticas Públicas, políticas culturais e museu no Brasil. Revista Museologia e Patrimônio, v. 2, p. 54-69, 2009.

23. MOSCOVICI, S. Representações: investigações em Psicologia Social. Rio de Janeiro: Vozes, 2011.

24. PINHEIRO, M. L. B. Origens da Noção de Preservação do Patrimônio Cultural no Brasil. Revista RISCO, EESC-USP, São Paulo, 2006, pp.4 -14.

25. POULOT, D. Uma história do patrimônio no Ocidente. São Paulo: Estação Liberdade, 2009.

26. RANGEL, M. F. Políticas públicas e museus no Brasil. In: Marcus Granato, Cláudia Penha dos Santos e Maria Lucia de Niemeyer Matheus Loureiro. (Org.). MAST Colloquia - O Caráter Político dos Museus. Rio de Janeiro: MCT, MAST, v. 12, p. 119-135, 2010.

27. RABELLO, S. O Estado na preservação de bens culturais: o tombamento. Rio de Janeiro: IPHAN, 2009.

28. REIS, A. A.; STARLING, M. B. de L.. Apontamentos sobre o ICMS patrimônio cultural. Belo Horizonte: Fundação João Pinheiro, 2002.

29. RUBIM, A. A. C. Conselhos de Cultura: atribuições, caráter, composição e democracia. In: RUBIM, Albino; FERNANDES, Taiane; RUBIM, Iuri (Org.). Políticas culturais, democracia e conselhos de cultura. Salvador: EDUFBA, 2010.

30. SANTOS, C. R. Novas fronteiras e novos pactos para o patrimônio cultural. São Paulo Perspectiva, São Paulo, vol.15, n.2, 2001, pp. 43-48.

31. SCHEINER, T. C. M.. Imagens do não-lugar: Comunicação e o patrimônio do futuro. Tese de doutorado em Comunicação Social. Programa de Pós-Graduação em Comunicação Social da Universidade Federal do Rio de Janeiro - UFRJ - Brasil, 2004.

32. O museu como processo. Caderno de diretrizes museológicas. Belo Horizonte: Superintendência de Museus, 2008.

33. STARLING, M. B. L. Patrimônio, participação local e democracia: o papel dos conselhos municipais de patrimônio cultural de Minas Gerais. Políticas Culturais em Revista, Belo Horizonte, v.1, 2009, pp. 140-156.

34. TATAGIBA, L. Os Conselhos e a Construção da Democracia no Brasil: um rápido balanço de duas décadas de participação conselhista. In: RUBIM, Albino; FERNANDES, Taiane; RUBIM, Iuri (Org.). Políticas culturais, democracia e conselhos de cultura. Salvador: EDUFBA, 2010.

35. VASCONCELLOS, L. M. de; MELLO, M. C. F. Terminologias em busca de uma identidade. Revista de Urbanismo e Arquitetura, América do Norte, v.6, dez. 2008.

36. VELOSO, M. M. S. O fetiche do patrimônio. Habitus (UCG. Impresso), v. 4, p. 437-454, 2006.

37. WALZER, M. Política e paixão. Rumo a um liberalismo mais igualitário. São Paulo: Ed. Martins Fontes, 2008 .

38. MINAS GERAIS, Instituto Estadual 
do Patrimônio Histórico e Artístico. Relatório de Atividades 1995-1998. Minas Gerais, 1998.

39. MINAS GERAIS, Instituto Estadual do Patrimônio Histórico e Artístico. Relatório de Atividades 1999-2002. Minas Gerais, 2002.

40. MINAS GERAIS, Instituto Estadual do Patrimônio Histórico e Artístico. Relatório de Atividades 2003-2006. Minas Gerais, 2006.

41. MINAS GERAIS, Instituto Estadual do Patrimônio Histórico e Artístico. Relatório de Atividades 2007-2010. Minas Gerais, 2010.

42. MINAS GERAIS, Lei $\mathbf{1 2 . 2 4 0}$ de 28 de dezembro de 1995. Legislação Estadual Governo do Estado de Minas Gerais. Disponível em: <http://www. fjp.mg.gov.br/robin-hood/index.php/ leirobinhood/legislacao/lei1204095> Acesso em 10 de julho de 2012.

43. MINAS GERAIS, Lei $\mathbf{1 2 . 4 2 8}$ de 27 de dezembro de 1996. Legislação Estadual Governo do Estado de Minas Gerais. Disponível em: <http://www. fjp.mg.gov.br/robin-hood/index.php/ leirobinhood/legislacao/lei1204095> Acesso em 10 de julho de 2012.

44. MINAS GERAIS, Lei $\mathbf{1 3 . 8 0 3}$ de 27 de dezembro de 2000. Legislação Estadual Governo do Estado de Minas Gerais. Disponível em: <http://www. fjp.mg.gov.br/robin-hood/index.php/ leirobinhood/legislacao/lei1204095> Acesso em 10 de julho de 2012.

45. MINAS GERAIS, Lei $\mathbf{1 8 . 0 3 0}$ de $\mathbf{1 2}$ de janeiro de 2009. Legislação Estadual Governo do Estado de Minas Gerais. Disponível em: <http://www.fjp. mg.gov.br/robin-hood/index.php/leirobinhood/legislacao/lei1204095> Acesso em 10 de julho de 2012.

46. MINAS GERAIS, Resolução 01/1996. Instituto Estadual do Patrimônio Histórico e Artístico. Belo Horizonte, 1996.
47. MINAS GERAIS, Resolução 01/1997. Instituto Estadual do Patrimônio Histórico e Artístico. Belo Horizonte, 1997.

48. MINAS GERAIS, Resolução 01/2000. Instituto Estadual do Patrimônio Histórico e Artístico. Belo Horizonte, 2000.

49. MINAS GERAIS, Resolução 01/2002. Instituto Estadual do Patrimônio Histórico e Artístico. Belo Horizonte, 2002.

50. MINAS GERAIS, Resolução 02/2002. Instituto Estadual do Patrimônio Histórico e Artístico. Belo Horizonte, 1996.

51. MINAS GERAIS, Resolução 01/2004. Instituto Estadual do Patrimônio Histórico e Artístico. Belo Horizonte, 2004.

52. MINAS GERAIS, Resolução 01/2005. Instituto Estadual do Patrimônio Histórico e Artístico. Belo Horizonte, 2005. 